\title{
Effect of metakaolin on early strength of GGBS ternary concrete
}

\begin{abstract}
The article reports a laboratory experimental programme that investigated effect of metakaolin on the early strength of concrete made with ternary combinations of Portland cement (CEM I) with ground granulated blast slag (GGBS) and metakaolin (MK). The various level of cement combinations $(65 \% \mathrm{CEM} \mathrm{I}+30 \% \mathrm{GGBS}+5 \% \mathrm{MK}, \quad 45 \% \mathrm{CEM}$ $\mathrm{I}+45 \% \mathrm{GGBS}+10 \% \mathrm{MK}$ and $45 \% \mathrm{CEM} \mathrm{I}+40 \% \mathrm{GGBS}+15 \% \mathrm{MK})$ was examined in comparison to CEM I and equivalent GGBS binary concretes for up to 28 days. Results show that the reduction in early strength is greater with the higher cement replacement level. However, the ternary concrete containing $15 \% \mathrm{MK}$ has minor increase in early strength compared to those with $10 \% \mathrm{MK}$ but a significant increase in strength is examined at later age (28 days). It is concluded that the presence of MK compensates the adverse effect of GGBS at early strength development and improves the strength at later ages.
\end{abstract}

Keyword: Binary; Early strength; GGBS ternary concrete; Heat of hydration; Metakaolin 